\title{
Jornalismo hiperlocal: projeto experimental Lupa $\mathrm{NH}^{1}$
}

HYPERLOCAL JOURNALISM: EXPERIMENTAL PROJECT LUPA NH

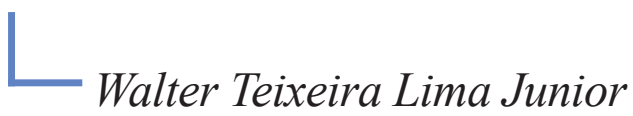

Pós-doutor no Dlab do Departamento de Mecatrônica da Escola Politécnica da Universidade de São Paulo e doutor em Ciências da Comunicação pela USP. É pesquisador do CNPq, professor da Universidade Federal do Amapá (Unifap) e docente do Programa de Pós-Graduação em Comunicação Cultura e Amazônia da Universidade Federal do Pará (UFPA), do Programa de Pós-Graduação em Ciências Ambientais (Unifap) e do Programa de Pós-Graduação em Propriedade Intelectual e Transferência de Tecnologia para a Inovação (Unifap)

E-mail: digital@walterlima.jor.br

Recebido em 13 de novembro de 2017. Aprovado em 31 de janeiro de 2018.

\section{Resumo}

O projeto experimental visa a elaboração de arcabouço teórico interdisciplinar e a criação de aplicativo para telefones celulares, estabelecendo a configuração de um ambiente comunicacional (conversação) e de deliberação para a formação de inteligência social hiperlocal. O espaço geográfico delimitado é o da comunidade de Novo Horizonte (Macapá/AP). O ambiente digital pensado tem como objetivo que moradores, jornalistas, frequentadores e conhecedores da região possam abastecer bases de dados digitais locais a partir de aplicativo para dispositivos móveis customizado e/ ou na Web, possibilitando a formação de datasets com informação estruturada sobre a região. $\mathrm{O}$ objetivo principal é a criação de uma esfera pública interconectada, composta pela "coesão coletiva" e pelo processo comunitário de deliberação. A instituição de um ambiente participativo por meio das tecnologias de comunicação conectadas fornece "poder" à comunidade, influenciando a tomada de decisões locais de forma colaborativa, o envolvimento cívico, a coprodução e o compartilhamento de informação com o fim de resolver os graves problemas sociais da região.

Palavras-chave: Experimental. Jornalismo. Hiperlocal. Tecnologia.

1 Artigo apresentado no $8^{\circ}$ Congresso Internacional de Ciberjornalismo, ocorrido de 27 a 29 de setembro de 2017, na Universidade Federal de Mato Grosso do Sul. 


\section{Abstract}

This experimental project aims to develop an interdisciplinary, theoretical framework and to create applications for mobile phones, configuring an environment of communication (conversation) and of deliberation on the formation of hyperlocal social intelligence. The geographical space chosen is that of the community of Novo Horizonte (Macapá/AP). The digital environment pondered aims to allow for residents, journalists, regulars and connoisseurs of the region to supply local digital databases through a customized mobile device application and/or a website, enabling formation of datasets with structured information about the region. The main objective is the creation of a interconnected public sphere, composed by "collective cohesion" and the community procedure of deliberation. The establishment of a participative environment through connected communication technologies provides power to the community, affecting local and collaborative decision-making, civic involvement, co-production and sharing of information in order to solve severe social problems in the region.

Keywords: Experimental. Journalism. Hyperlocal. Technology.

\section{Introdução}

Este relato visa compartilhar os primeiros resultados da pesquisa experimental que está sendo realizada na comunidade de Novo Horizonte, na cidade de Macapá, Amapá. O projeto teve início em junho de 2017 por intermédio de atividades como reuniões, visitas ao bairro, à rádio comunitária e à escola Estadual Raimunda dos Passos Santos, além do Hackathon $^{2}$, com o objetivo de iniciar o desenvolvimento de aplicativo móvel, doravante denominado Lupa NH (Lupa Novo Horizonte).

O relato de experiência contido neste artigo visa demonstrar as fases contidas no projeto empírico com o objetivo de ampliar a compreensão e a fundamentação da teoria sobre comunicação e conceitos atuais de hiperlocal, tendo como foco o jornalismo. Por ser um projeto que necessita de apoio e cooperação da comunidade onde será testado, os resultados colaborarão para a práxis metodológica da área.

O Projeto Lupa NH possui a meta de incentivar a cidadania dos moradores, trabalhadores e frequentadores do Bairro Novo Horizonte por intermédio de tecnologias

2 “'Hackathon (palavra-valise inglesa, formada pelos vocábulos to hack, 'fatiar', 'quebrar', 'alterar ou ter acesso a um arquivo ou rede' e marathon, maratona), termo eventualmente aportuguesado para 'hackaton', é uma maratona de programação na qual hackers se reúnem por horas, dias ou até semanas, a fim de explorar dados abertos, desvendar códigos e sistemas lógicos, discutir novas ideias e desenvolver projetos de software ou mesmo de hardware. Por ser um evento público (também referido como hack day, hackfest ou codefest), a maratona dá visibilidade e transparência a essas atividades, além de divulgar os novos produtos gerados" (HACKTON, 2017). 
digitais conectadas móveis. Com ajuda de aplicativo para celular criado para esse fim, os usuários desse sistema poderão, de forma geolocalizada, inserir dados sobre o bairro, alimentando o banco de dados (dataset) com informações sobre a infraestrutura deficitária nas seguintes áreas: água potável; coleta e tratamento de esgoto; iluminação pública; calçadas; asfalto; limpeza urbana.

Com introdução de inovações no campo das tecnologias digitais conectadas e a popularização de dispositivos móveis, tendo como carro-chefe os smartphones, outras formas de produção de informação jornalística local estão emergindo, principalmente com a ação direta dos atores sociais que pertencem à comunidade. Através deles, com a utilização de dispositivos móveis e sistemas produzidos especificamente com objetivo de coletar dados, informações locais são armazenadas, relacionadas, correlacionadas e visualizadas, fornecendo infinitas possibilidades de construção de narrativas de relevância social, ajudando a comunidade na tomada de decisões sobre os melhores caminhos para resolver problemas que os afligem coletivamente. (LIMA JUNIOR; COELHO, 2015, p. 2).

O bairro de Novo Horizonte foi escolhido pelos integrantes do projeto por ser a segunda maior comunidade em população de Macapá. De acordo com estimativas atuais, o número está em torno de 45 mil habitantes. Novo Horizonte possui uma história de comunicação comunitária: o bairro possui uma rádio comunitária e já teve um jornal impresso feito pela comunidade.

\section{Comunidade Novo Horizonte}

A comunidade Novo Horizonte no passado era conhecida por Capilândia, sendo que o bairro surgiu em um grande loteamento na época do governo estadual de João Capiberibe. Depois de quase 30 anos, o bairro cresceu, a área foi dividida e ganhou novos nomes: Novo Horizonte II e III. O bairro possui 272 quadras e a maioria dos moradores é composta de migrantes do nordeste do país, de modo que há poucos amapaenses natos na região.

Localizado na zona norte de Macapá, é considerado o maior bairro do município em área e o segundo mais populoso. Em 2010, de acordo com o Instituto Brasileiro de Geografia e Estatística (IBGE), Novo Horizonte tinha 24.360 habitantes, sendo 11.996 homens $(49,2 \%)$ e 12.364 mulheres $(50,8 \%)$. Em população, a região perdia apenas para o bairro de Buritizal, que tinha 25.651 habitantes.

Além disso, na região havia 5.782 domicílios particulares permanentes, distribuídos em uma área de 15,3 quilômetros quadrados. 


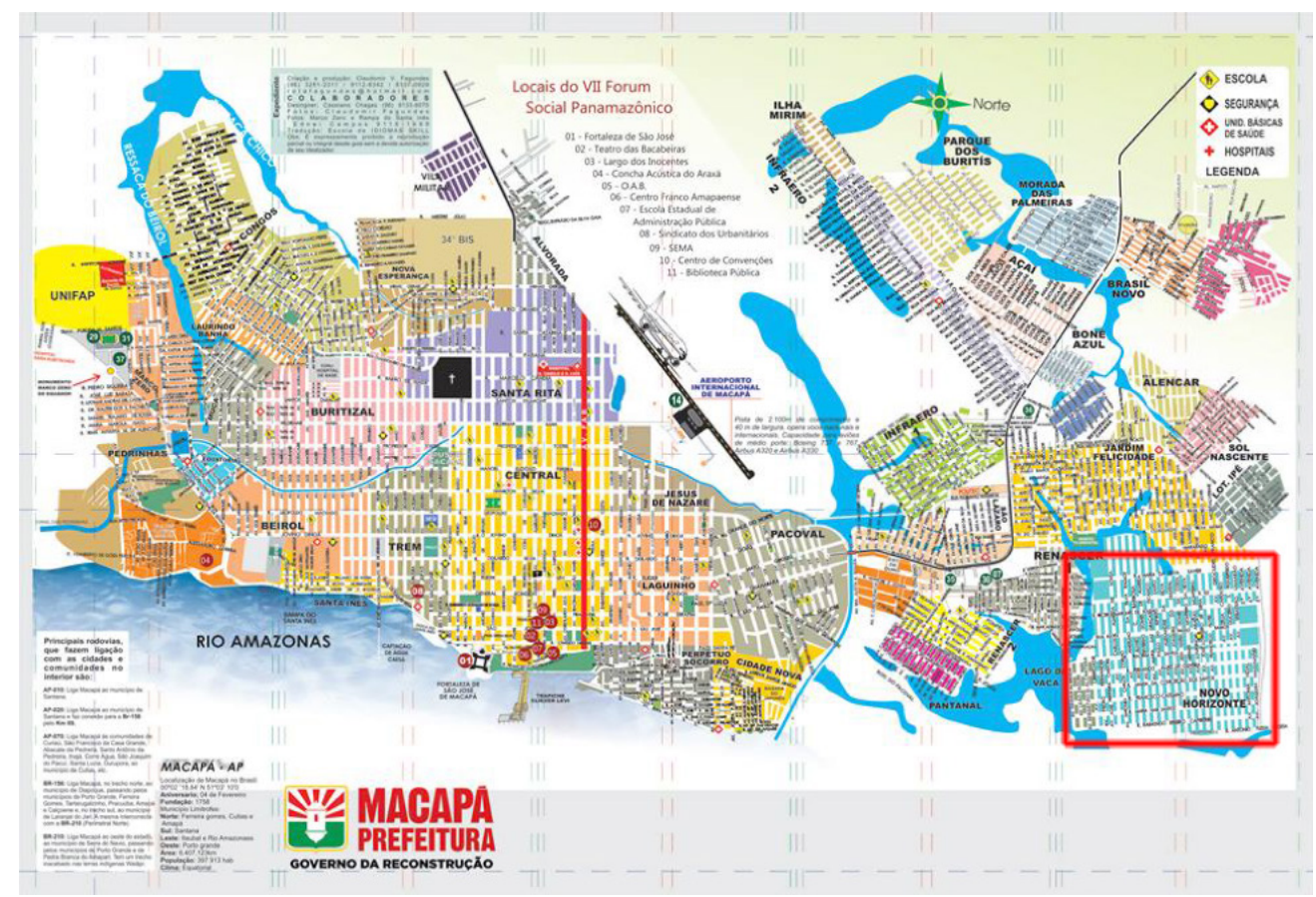

Figura 1. Bairro Novo Horizonte

Fonte: VII Fórum Social Panamazônico, 7 fev. 2017.

As carências e dificuldades enfrentadas pelos moradores referem-se à falta de segurança pública, às condições das vias públicas, ao transporte urbano, ao sistema educacional, ao abastecimento de água e ao saneamento básico. Em 2016, o jornal local $A$ Gazeta elaborou uma reportagem sobre os problemas do bairro (BAIRRO..., 2016). A população reclama de problemas que deveriam ter sido solucionados pela prefeitura de Macapá. Na reportagem, os moradores apontam dificuldades em relação à infraestrutura local, como problemas no transporte público, calçadas, saneamento básico, coleta de resíduos e ausência de um poder público atuante.

O bairro possui um centro comercial com feira, lojas, agências bancárias, agência dos Correios, casa lotérica e um Centro Integrado de Operações em Segurança Pública (CIOSP). Em 2014, a Polícia Civil do Amapá instalou no CIOSP uma Unidade de Polícia Comunitária (UPC) (SILVA, J. M., 2014). Também em 2014, a região ganhou a Unidade de Pronto Atendimento (UPA) Novo Horizonte (SILVA, A., 2016).

\section{Projetos interligados}

O Projeto Lupa NH possui equipe formada pelos estudantes de Jornalismo da Universidade Federal do Amapá (Unifap) Christopher Ferreira, Delano Borges e Alena Tavares, como também e por Anderson Guerra, do curso de Ciências da Computação.

$70 \frac{\text { Comunicação \& Inovação, PPGCOM/USCS }}{\text { v. 19, n. } 39 \text { (67-81) jan-abril } 2018}$ 
Também há participação do jornalista e mestre em Comunicação pela Universidade Metodista de São Paulo Cido Coelho. O projeto, além de congregar, inicialmente, alunos do curso de Jornalismo e Ciências da Computação, é composto por dois colaboradores-voluntários que participaram do Hackathon, Altemir Almeida e Felipe Ferreira, que ajudam na elaboração técnica do aplicativo. $\mathrm{O}$ evento foi realizado no dia 4 de março de 2017 (sábado), das 08:00 às 17:00 horas, no laboratório de Webjornalismo da Unifap³.

A acadêmica Alena Paula Corrêa Tavares desenvolveu por 12 meses (de julho de 2016 a agosto de 2017), contribuindo para a modelagem do Projeto Lupa NH, a pesquisa "Tecnologias do jornalismo hiperlocal na construção da cidadania", por intermédio do Programa Institucional de Bolsas de Iniciação em Desenvolvimento Tecnológico e Inovação (PIBITI) do Conselho Nacional de Desenvolvimento Científico e Tecnológico (CNPq) da Unifap, promovido pelo edital nº 18/2016 do Núcleo de Inovação e Transferência de Tecnologia (NITT) desta universidade. Essa pesquisa esteve vinculada ao projeto Bolsista de Produtividade PQ (2016-2019), desenvolvido pelo autor deste texto, intitulado "Inteligência social hiperlocal: ambiente comunicacional com dados locais gerados pela comunidade". O projeto visa elaborar arcabouço teórico interdisciplinar e modelar sistemas para a configuração de ambiente comunicacional (conversação) e de deliberação para a formação de inteligência social hiperlocal, tendo um espaço geográfico delimitado (na atualidade, o bairro Novo Horizonte). $\mathrm{O}$ ambiente digital será projetado com o objetivo de que moradores, jornalistas, frequentadores e conhecedores da região possam abastecer bases de dados locais a partir de aplicativo customizado para dispositivos móveis e/ou website, possibilitando a criação de datasets com informação estruturada sobre a área. $\mathrm{O}$ sistema proposto tem como objetivo principal o estabelecimento de uma esfera pública interconectada, composta pela "coesão coletiva" e pelo processo de deliberação. A instituição de um ambiente participativo por meio das tecnologias de comunicação conectadas fornece "poder" à comunidade, influenciando a tomada de decisões locais de forma colaborativa, o envolvimento cívico, a coprodução e o compartilhamento de informações a fim de resolver os graves problemas sociais da região.

\section{Conceito de hiperlocal}

$\mathrm{Na}$ atualidade, uma das grandes dificuldades enfrentadas pelos publishers que atuam no jornalismo digital conectado é encontrar modelos de negócios que possuem foco no espaço geográfico local, visando a produção de conteúdo informativo de relevância

3 A chamada para o evento de Hackathon está disponível no endereço a seguir: <https://goo.gl/TPqR6S $>$. Acesso em: 25 set. 2017. 
social, mas que não sejam metáforas de produtos oriundos das ditas mídias tradicionais. Muito do que se apresentou na web nesses últimos 20 anos de internet comercial, no campo do jornalismo, são projetos baseados em produtos consagrados da mídia tradicional.

Também a tarefa de criar produtos locais que tenham relevância tem encontrado dificuldade devido à globalização da informação, pavimentada pelo fluxo livre de informação imposto pela rede telemática da internet. Outro fator não lateral é que a informação local ou de proximidade, como conceituam alguns pesquisadores espanhóis, não tem tanta atenção na audiência da web como a informação de cunho global.

Um dos motivos tecnológicos para o fluxo de informação global é que a estrutura da internet tem promovido conexões entre as pessoas em todo o mundo devido à sua descentralização e baixa hierarquia, permitindo que todos que estejam conectados na rede sejam produtores e transmissores de informação. Sua organização é baseada na arquitetura de rede idealizada topologicamente por Paul Baran, em 1964.
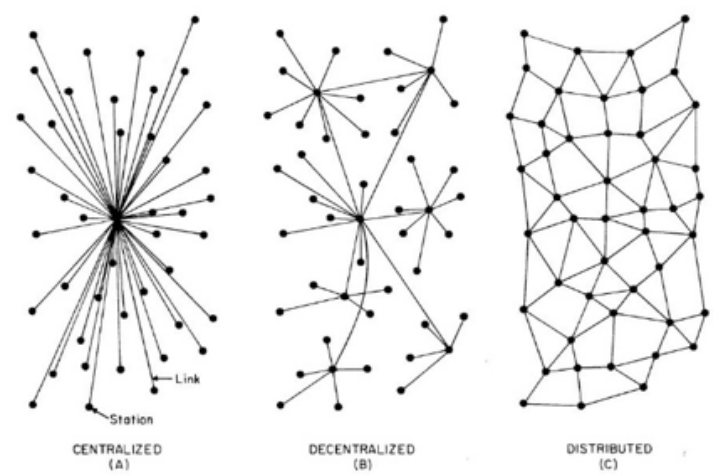

Figura 2. Diagrama de Paul Baran (1964)

Fonte: Baran, 1964.

Para que a topologia de Paul Baran funcionasse, Vinton Cerf e Bob Kahn criaram o protocolo TCP/IP ${ }^{4}$ e o implantaram com sucesso em 1969. A camada user-friendly da internet (WWW) é criada em 1989 por Berners-Lee. Nesse momento, a web faz que a

4 "O TCP/IP (também chamado de pilha de protocolos TCP/IP) é um conjunto de protocolos de comunicação entre computadores em rede. Seu nome vem de dois protocolos: o TCP (Transmission Control Protocol Protocolo de Controlo de Transmissão) e o IP (Internet Protocol - [...] Protocolo de Interconexão). O conjunto de protocolos pode ser visto como um modelo de camadas [...], onde cada camada é responsável por um grupo de tarefas, fornecendo um conjunto de serviços bem definidos para o protocolo da camada superior. As camadas mais altas estão logicamente mais perto do usuário (chamada camada de aplicação) e lidam com dados mais abstratos, confiando em protocolos de camadas mais baixas para tarefas de menor nível de abstração" (TCP/IP, 2006). 
inserção e a visualização de informações sejam possíveis por qualquer ator que tenha uma máquina computacional e conexão com a rede.

Portanto, o modelo de rede de Paul Baran, a inovação trazida pelo protocolo TCP/ IP de Cerf e Kahn e a "camada amigável" elaborada por Berners-Lee possibilitaram que a configuração topológica fosse apropriada por atores sociais, permitindo que o fluxo informativo passasse a ser global. Contudo, apesar da facilidade de produção e compartilhamento de informação, há um grande obstáculo na criação de fluxo informativo de caráter local e de proximidade, no sentido de formação de comunidade. Para que isso aconteça, o conjunto de informações deve ter caráter sinérgico. Há uma pequena confusão, vale ressaltar, quando se afirma que mídias tradicionais locais (TV, rádio, jornal impresso etc.) são naturalmente hiperlocais por terem programas e temas direcionados à comunidade local, como também aos portais noticiosos ligados a grupos de mídias locais ou independentes. Entretanto, esse modelo de disseminação de notícias, apesar do sucesso comercial, em muitos casos, não se mostra suficiente para criar e alavancar a conversação estruturada sobre questões e temas locais de interesse coletivo pois, apesar de local, seu interesse está em comunicar os fatos noticiosos e não em fazer curadoria ou estabelecer processos deliberativos a respeito deles.

Nesse sentido, as tecnologias digitais conectadas podem proporcionar, quando são criados sistemas para tal finalidade, o surgimento de um espaço de intervenção humana colaborativo, que viabiliza a abertura de um campo de discussão e o estabelecimento de uma esfera pública interconectada (BENKLER, 2006). As tecnologias digitais conectadas são utilizadas na discussão de questões de caráter público, pois possibilitam vários níveis de interatividade entre os seus usuários e possuem espaços específicos para tal finalidade.

Segundo a pesquisadora Ângela Cristina Salgueiro Marques (2011, p. 38), os princípios normativos envolvidos nos processos deliberativos on-line devem conter: "discussão crítico-racional (viés da inclusão e publicização de entendimento plurais); discussão crítico-racional, reciprocidade, reflexividade, liberdade participativa e igualdade discursiva".

O impacto social de cidadãos discutindo em rede temáticas que abarcam seus interesses locais (vizinhança) produz implicações para as autoridades locais. Trata-se de uma forma organizada de discussão de temas relevantes para a localidade que se transforma em conteúdo estruturado, servindo como elemento de pressão sobre as autoridades responsáveis.

Portanto, a formação de comunidades por intermédio de discussões sobre assuntos locais de relevância social é fundamental para que as reações e relações informativas do conjunto de habitantes que moram e convivem em um determinado espaço geográfico tenham a força da autenticidade. Essa sinergia informativa é importante para traçar bons propósitos em prol da resolução de problemas da localidade, podendo se constituir em autoridade 
pública para explicar ou expressar a democracia de forma inovadora (RADCLIFFE, 2012, p. 3). Segundo Radcliffe (2012), se essa condição for cumprida, o termo hiperlocal será um conceito adequado para descrever essa sinergia informativa geolocalizada.

Entretanto, o conceito de jornalismo hiperlocal muitas vezes refere-se à cobertura de fatos noticiosos em um bairro ou até mesmo uma quadra (WALDMAN, 2011). No processo clássico de intermediação da comunicação encontram-se os jornalistas que, em contato com a comunidade, permitem o envolvimento do conjunto de indivíduos que mora ou frequenta uma determinada localidade - como trabalhadores, ativistas, jovens e o público em geral -, com as seguintes finalidades: compartilhar os problemas da comunidade; elaborar estratégias de organização e chamamento para a ação; compartilhar pesquisas e resultados da comunidade envolvida de forma participativa; proporcionar o conhecimento geral sobre o trabalho da comunidade, conquistas e eventos. Esse modelo de comunicação permite expandir, compartilhar e usar a pesquisa para levantar questões e estratégias, abrindo a porta para a comunidade local compartilhar informações (BURNS; BONILLA, 2012, p. 5). O foco conceitual, descrito anteriormente, foi estruturado de acordo com o desenvolvimento histórico do jornalismo comunitário, que tem como base a produção de notícias para leitores e/ou usuários locais.

Os processos de desenvolvimento e apropriação de inovações tecnológicas são constantes e por meio deles emergem novas possibilidades de produzir e consumir informação de relevância social. Dessa forma, o surgimento de novos modelos de negócios e formatos no campo do jornalismo é colocado à prova, ou seja, se sobrevive comercialmente e/ou como serviço de utilidade pública.

As tecnologias digitais conectadas, em conjunto com as chamadas mídias tradicionais (TV, rádio e jornal impresso), estão produzindo um novo ecossistema informativo. Portanto, alguns conceitos de comunicação social também estão mudando e ampliando o seu significado. Nesse caso, a definição de comunicação hiperlocal está sendo modificada nos últimos anos, alterando o seu significado para outros entendimentos conceituais.

De acordo com Metzgar, Kurpius e Rowley (2011), a definição contemporânea de hiperlocal vai além da produção de website com escopo de jornalismo comunitário voltado para uma determinada localidade. No sentido de fornecer nova definição para mídia hiperlocal, esses pesquisadores propõem um quadro de discussão, discutindo uma nova abordagem para definir a ideia, o Operação de Mídia Hiperlocal.

Concentrando-se em elementos geográficos, orientação para a comunidade, relatórios de notícias originais, origens na web, preenchendo lacunas percebidas e engajamento cívico, mostramos como a combinação destas categorias apresenta um quadro abrangente para identificar e analisar as Operações de Mídia Hiperlocal. Nossa discussão aqui demonstra que 
hiperlocalidade não existe como um ponto solitário em uma única medida. Em vez disso, ele é um composto de medidas em uma variedade de contínuos, que vão desde aspectos geográficos para as perspectivas de engajamento cívico. (Ibid., p. 775).

Para Radcliffe (2012), o jornalismo hiperlocal tem sua missão no fornecimento “de notícias, conteúdo ou serviços on-line pertencentes a uma cidade, vila, único código postal ou outra comunidade pequena, geograficamente definido". O seu principal atributo é focalizar um determinado espaço geográfico restrito ou tópico especializado (FOUST, 2009) ou assunto de nicho, cujo tema é uma pequena área geográfica.

O termo, segundo a argumentação contida neste artigo, é utilizado para definir informações locais, que são debatidas pela comunidade e jornalistas profissionais. No entanto, essa definição é bem aceita em estudos sobre a representação das comunidades a partir das redes. Adota-se neste projeto o conceito que a Comunicação Hiperlocal está focalizada em uma pequena área geográfica, permitindo que o conceito de Jornalismo Hiperlocal surja por intermédio de sistemas digitais conectados que concentram informação local de relevância social. A informação é inserida pela comunidade, por frequentadores e/ou jornalistas, apoiados por tecnologias sociais e sistemas inteligentes baseados em dados, a fim de melhorar a tomada de decisões de uma comunidade específica, geograficamente delimitada (cidade inteira ou única região da cidade), e de alcançar desenvolvimento social. Outro atributo forte está ligado à necessidade de comunicação hiperlocal, mediada por sistemas computacionais digitais conectados, para ajudar a envolver as pessoas em sua comunidade.

\section{Pesquisa interdisciplinar e experimental}

O projeto possui escopo interdisciplinar, pois envolve áreas do conhecimento da Comunicação Social (Jornalismo) e Ciência da Computação. No plano interdisciplinar, a situação é idêntica ao do disciplinar, só que agora com uma integração dos respectivos domínios linguísticos de cada disciplina. Essa integração é permitida, facilitada e orientada pela existência de uma temática comum a todas essas disciplinas, a partir da qual elas deverão observar o objeto. Como resultado desse modo de produção, continua-se tendo três textos, porém cada um refletindo parte da realidade, dentro do domínio linguístico das outras disciplinas. Esse modelo de trabalho exige a cooperação e a coordenação entre as disciplinas (ALVARENGA et al. 2016).

Nessa fase do projeto, a pesquisa está na transição da pesquisa pura/fundamental/ básica para a área da pesquisa experimental, ou seja, aplicação da modelagem do aplicativo para celular em um sistema computacional. Na pesquisa experimental, o experimento pode estar fora do ambiente laboratorial, contanto que haja interferência do pesquisador em um 
aspecto da realidade e sejam desenvolvidas técnicas rigorosas de controle sobre as variáveis, a fim de se observar as relações de causalidade entre elas (LIMA JUNIOR, 2015, p. 64).

\section{Projeto}

Embasado nos conceitos contemporâneos de comunicação hiperlocal, o Projeto Lupa NH promove a colaboração dos membros da comunidade com a intenção de estruturar dados e configurar por meio deles a real situação da infraestrutura fornecida pelo poder público aos moradores do bairro. Sendo a própria comunidade responsável por abastecer o aplicativo com dados relevantes sobre o meio que habita, ela se comprometerá com ações que pressionem os entes públicos a transformarem a realidade da infraestrutura do lugar, de acordo com as demandas elencadas como prioridades.

Depois de realizar revisão bibliográfica e tecnológica sobre a temática, a atual fase do projeto contempla a modelagem do aplicativo. O Lupa $\mathrm{NH}$ possui o apoio de dois agentes transformadores e importantes no bairro: o professor Lobão, que comanda os projetos na área de comunicação da escola Raimunda dos Passos, e a acadêmica de jornalismo Jéssica Janyelle (Estácio/Seama), que é uma das responsáveis pela rádio comunitária do Novo Horizonte.

Para dar ampla divulgação ao projeto e conquistar participantes, foram abertos perfis nas redes sociais Facebook ${ }^{5}$ e Twitter $^{6}$. Essa ação permitirá maior proximidade entre os envolvidos e trará visibilidade para o bairro Novo Horizonte, dando voz à comunidade para expor a realidade local e na busca de melhorias significativas na qualidade de vida.

\section{Método}

Com o objetivo de proporcionar a emergência de informações relevantes que garantam tomadas de decisões estruturadas para o desenvolvimento sustentável da comunidade de Novo Horizonte, ajudando a resolver seus principais problemas de forma participativa e democrática, o método experimental interdisciplinar contemplou as seguintes etapas: compilação de revisão bibliográfica e documental; levantamento de dados sociais do Bairro Novo Horizonte; levantamento de sistemas digitais conectados para produção de jornalismo hiperlocal por intermédio de pesquisa na Web, elencando os sistemas mais adequados aos objetivos do projeto; aprimoramento da modelagem do aplicativo; aprimoramento e testes do aplicativo na comunidade de Novo Horizonte.

5 Consulte o Facebook do projeto em: <https://goo.gl/6hNdV6>. Acesso em: $1^{\circ}$ mar. 2018.

6 Consulte o Twitter do projeto em: <https://goo.gl/wrPdRj>. Acesso em: $1^{\circ}$ mar. 2018. 
$\mathrm{Na}$ atual fase de aplicação do projeto, estamos aprimorando o sistema de visualização de dados na web para execução de ações com a participação dos estudantes da escola Raimunda dos Passos, inserção de dados pela comunidade e produção de material jornalístico a partir dos dados coletados.

Ao longo desses meses, obtivemos diversos resultados que consideramos necessários para a evolução do projeto, para atender às questões colocadas pelos seus objetivos e que, ao mesmo tempo, auxiliam na construção do aplicativo.

Para o andamento do projeto, as reuniões trouxeram resultados que direcionaram o trabalho para diferentes caminhos. A partir delas, pudemos esclarecer como o projeto funcionaria e entender qual a importância dos cidadãos do bairro Novo Horizonte para a sua consolidação. Também pudemos constatar outros resultados esperados, determinando dias para visitas em campo e como realizaríamos o Hackathon, etapas do projeto que integraram mais colaboradores para auxiliar nas atividades, buscando melhorias nas ações executadas.

Foram realizadas visitas ao bairro Novo Horizonte que nos permitiram conhecer melhor os outros projetos jornalísticos que lá atuam. Pudemos estabelecer contato com pessoas-chave da comunidade, que nos explicaram mais sobre a rotina do bairro e sobre como é viver lá. A partir das visitas, enxergamos o bairro por outro ângulo e entendemos melhor porque o escolhemos. Foi durante as visitas que determinamos alguns pontos importantes para a construção do aplicativo e pudemos confirmar o quanto o jornalismo é importante para os cidadãos como instrumento de reivindicação para despertar a atenção dos governos estadual e municipal na tentativa de chamar a atenção para o bairro e sua nítida falta de estrutura.

A pesquisa-ação permitiu determinar os pontos da infraestrutura deficitária do bairro Novo Horizonte para que chegássemos aos dados necessários para moldar o aplicativo e colocá-lo em funcionamento. Como resultado da pesquisa-ação, obtivemos como resposta dos cidadãos do bairro uma lista que elenca os principais problemas a serem resolvidos, além de contribuir trazendo colaboradores para o projeto.

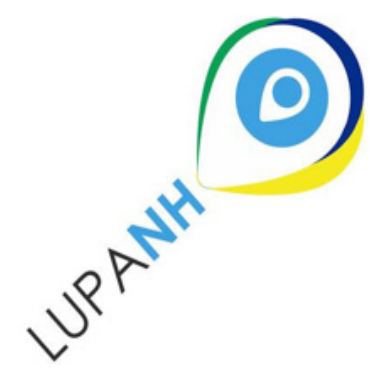

Figura 3. Logo do projeto elaborado por Válber de Souza Marinho Pimenta 


\section{MAPA LUPANH}

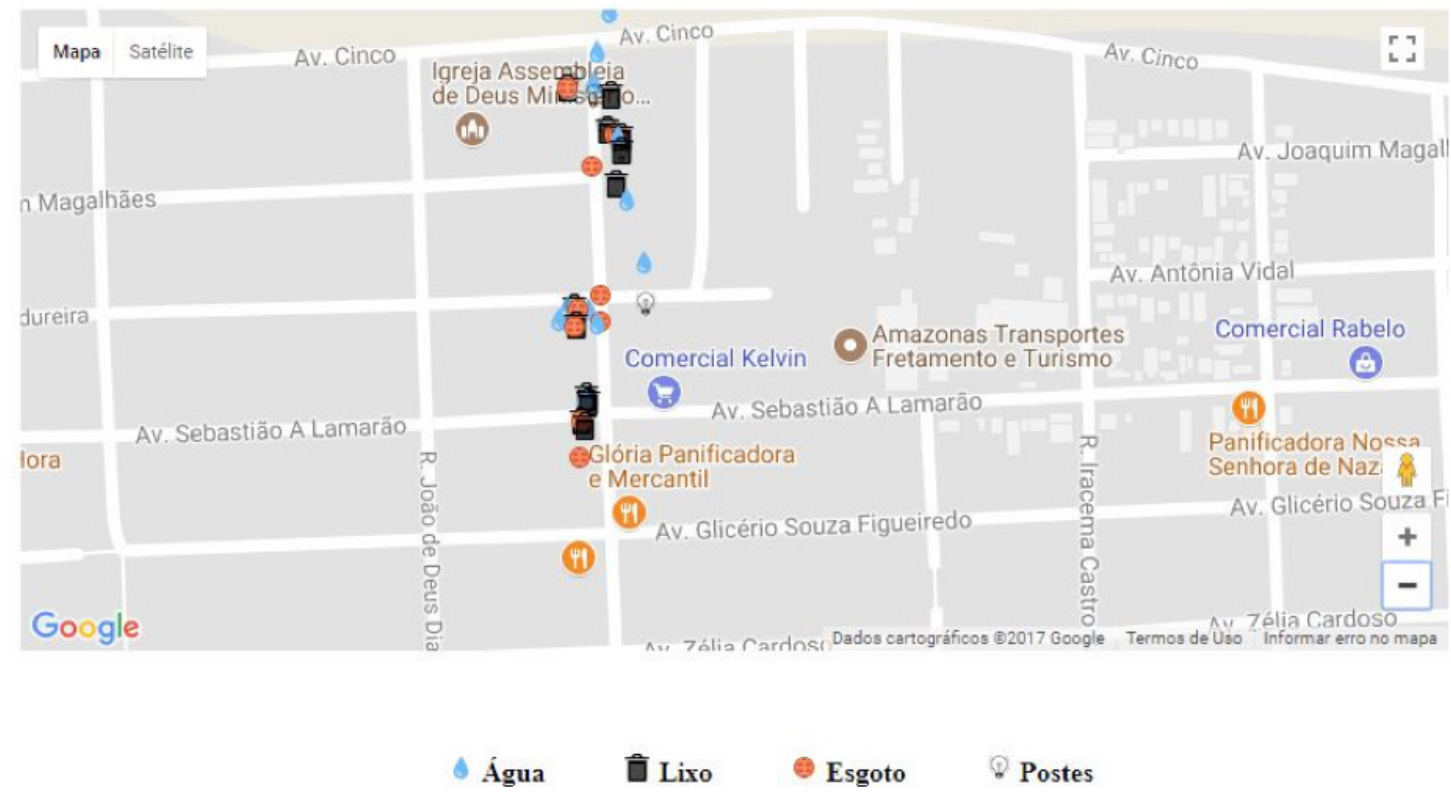

Figura 4. Visualização dos dados pela API do Google Maps

Fonte: Google Maps, 8 ago. 2017.

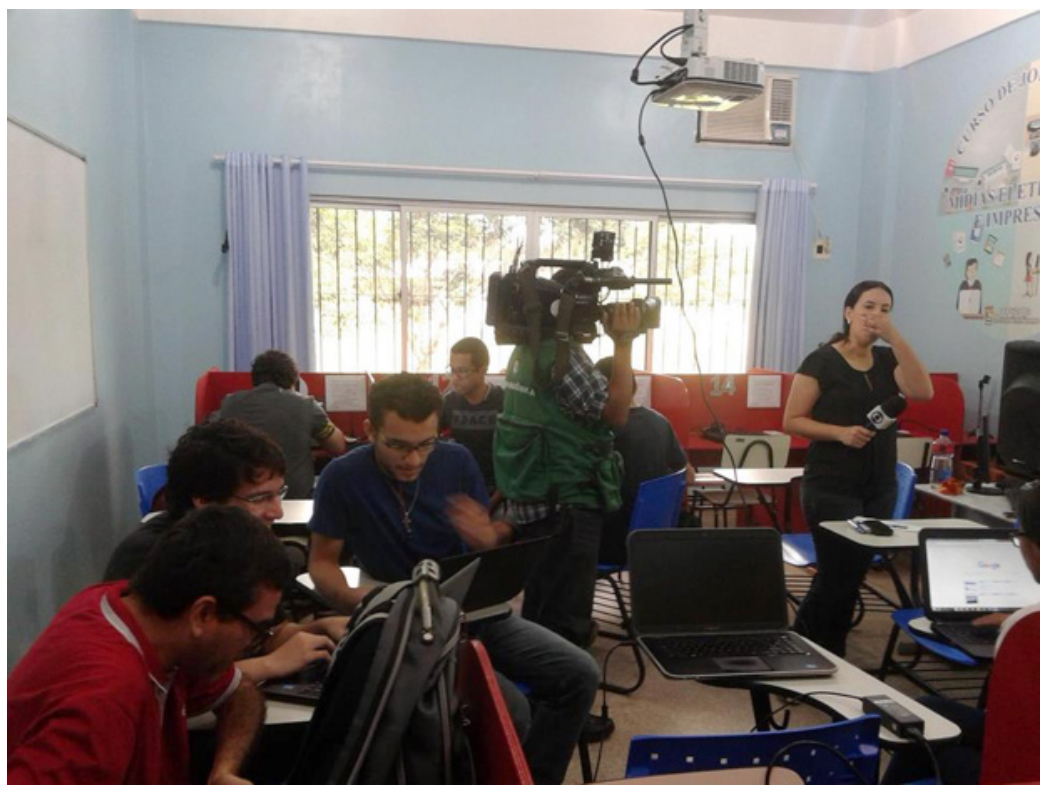

Figura 6. Realização do Hackathon

$78 \frac{\text { Comunicação \& Inovação, PPGCOM/USCS }}{\text { v. 19, n. } 39 \text { (67-81) jan-abril } 2018}$ 


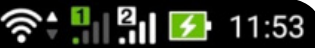

Home

Asfalto

lluminação

Água

Coleta de lixo

Esgoto

Figura 7. Protótipo da interface do aplicativo

\section{Resultados esperados}

Pesquisar e modelar conceitualmente jornalismo hiperlocal e associar seus atributos às tecnologias digitais conectadas disponíveis na web, a partir do aplicativo para celulares Lupa NH, permitirá o avanço técnico-científico por intermédio de pesquisa experimental para a criação de cultura sinérgica, utilizando processos de discussão de conteúdo, com relevância social hiperlocal. Isso contribui para a deliberação de soluções embasadas nas discussões oriundas da comunidade de Novo Horizonte, que podem ser utilizadas na produção de conteúdo jornalístico publicado na mídia local e nas redes sociais.

O Projeto Lupa NH visa, então, fornecer ferramental tecnológico (aplicativo móvel e visualização de dados) à comunidade de moradores e frequentadores do bairro Novo Horizonte, com o objetivo de produzir dados estruturados geolocalizados a respeito de algumas das suas principais carências estruturais - que estão se acentuando ao longo do tempo. O projeto tem como fim, dessa maneira, chamar a atenção da sociedade amapaense para a situação do bairro e servir de guia para debates sobre as questões envolvidas, alavancando ações de cidadania nessa região de Macapá.

\section{Referências}

ALVARENGA,A.T.;ALVAREZ,A. M. S.; SOMMERMAN,A.; PHILIPPI JUNIOR,A. Interdisciplinaridade e transdisciplinaridade nas tramas da complexidade e desafios aos processos investigativos. In: 
PHILIPPI JUNIOR, A.; FERNANDES, V. (Eds.). Práticas da interdisciplinaridade no ensino e na pesquisa. São Paulo: Manole, 2016, p. 341-342.

BAIRRO Novo Horizonte: a população enfrenta problemas que já deveriam ter sido solucionados pela Prefeitura. A Gazeta. Jornal Verdade, Macapá, 6 mar. 2016. Disponível em: $<$ https://goo.gl/vgho7r>. Acesso em: 25 set. 2017.

BARAN, P. On distributed communications: I. Introduction to distributed communication networks. Santa Monica: The Rand Corporation, 1964. Memorandum prepared for United States Air Force Project Rand.

BENKLER, Y. The wealth of networks: how social production transforms markets and freedom. New Haven; London: Yale University Press, 2006. Disponível em: <https://goo.gl/JSQtSB>. Acesso em: $1^{\circ}$ mar. 2018.

BURNS, J. C.; BONILLA, T. Hyperlocal communication. Report Advancement Project, 2012.

FOUST, J. C. Online journalism: principles and practices of news for the web. $2^{\text {nd }}$ ed. Scottsdale: Holcomb Hathaway, 2009.

HACKATHON. Wikipédia, [S.1.], 11 ago. 2017. Disponível em: <https://goo.gl/mqWwM2>. Acesso em: 25 set. 2017.

LIMA JÚNIOR, W. T. Projeto Rede JorTec: produção colaborativa de pesquisa visando à experimentação e criação de inovações tecnológicas digitais. Comunicação \& Sociedade, São Bernardo do Campo, v. 37, n. 1, p. 47-68, jan.-abr. 2015.

LIMA JÚNIOR, W. T.; COELHO, A. A. S. Captação de dados pela comunidade para a formação de inteligência social hiperlocal. In: CONGRESSO BRASILEIRO DE CIÊNCIAS DA COMUNICAÇÃO, 38., 2015, Rio de Janeiro. Anais... Rio de Janeiro: Intercom, 2015, p. 1-15.

MARQUES, Â. C. S. Aspectos teórico-metodológicos do processo comunicativo de deliberação online. Revista Brasileira de Ciência Política, Brasília, DF, n. 6, p. 19-40, jul.-dez. 2011. Disponível em: $<\mathrm{https}: / /$ goo.gl/G2s5X9>. Acesso em: $1^{\circ}$ mar. 2018.

METZGAR, E. T.; KURPIUS, D. D.; ROWLEY, K. M. Defining hyperlocal media: proposing a framework for discussion. In: ANNUAL MEETING OF THE INTERNATIONAL COMMUNICATION ASSOCIATION, 2011, Suntec City. Suntec City: Suntec Singapore International Convention \& Exhibition Centre, 2011. Unplibished manuscript. Disponível em: <https://goo.gl/YcsZuv>. Acesso em: 25 set. 2017.

RADCLIFFE, D. Here and now: UK hyperlocal media today. London: Nesta, 2012.

SILVA, J. M. CIOSP Novo Horizonte será transformado em unidade de polícia comunitária. Polícia Civil do Estado do Amapá, Macapá, 8 ago. 2014. Disponível em: <https://goo.gl/y5T6qX>. Acesso em: 25 set. 2017.

$80 \frac{\text { Comunicação \& Inovação, PPGCOM/USCS }}{\text { v. 19, n. } 39 \text { (67-81) jan-abril } 2018}$ 
SILVA, A. UPA do Novo Horizonte completa dois anos com mais de 1,5 milhão de procedimentos. Governo do Estado do Amapá, 26 out. 2016. Disponível em: <https://goo.gl/WxZD7N>. Acesso em: $1^{\circ}$ mar. 2018.

TCP/IP. Wikipédia, [S.1.], 7 mar. 2006. Disponível em: <https://goo.gl/WkWKE7>. Acesso em: 24 nov. 2017.

WALDMAN, S. The information needs of communites: the changing media landscape in a broadband age. Washington, DC: Federal Communications Commision, 2011. Disponível em: $<$ https://goo.gl/TPXwpS>. Acesso em: 25 set. 2017. 